\title{
USE OF REMOTE SENSING TO ANALYSE PEATLAND CHANGES AFTER DRAINAGE FOR PEAT EXTRACTION
}

Ali Torabi Haghighi ${ }^{1}$, Meseret Walle Menberu ${ }^{1}$, Justice Akanegbu ${ }^{1}$, Hamid Darabi $^{2}$ and Bjørn Kløve ${ }^{1}$

${ }^{1}$ Water Resources and Environmental Engineering Research Unit, University of Oulu, Finland.

${ }^{2}$ Sari Agriculture Science and Natural Resources University, Watershed management department, Sari, Iran

Corresponding author: Ali Torabi Haghighi,

Full address: P.O. Box 8000, FI-90014, University of Oulu, Finland,

Fax: +358 8344 084, Tel. +358404492894

Email: ali.torabihaghighi@oulu.fi,

\begin{abstract}
Large-scale peat extraction, carried out in Finland and elsewhere, typically takes place on rather small extraction sites, but has major impacts on surrounding aquatic and terrestrial ecosystems. The environmental conditions prior to drainage (baseline conditions) must be quantified in statutory environmental impact assessment (EIA), but this is generally difficult due to lack of historical data. In this study, we developed and tested a method for EIA based on a reference area approach and remote sensing. The method calculates the normalized difference vegetation index (NDVI) in pre- and postextraction periods using Landsat images of impacted areas and reference surrounding areas. The technique was applied to assess changes after peat extraction at a site in Northern Finland. The peat extraction area showed significant transformation from peatland vegetation to bare soil. Adjacent areas downstream and upstream were also affected by extraction. The results indicate that the method is a useful tool for EIA of peatland drainage.
\end{abstract}

Keywords: Wetlands, NDVI, peatlands, land use, remote sensing, disturbance. 


\section{Introduction}

About $12.5 \%$ of the total land area of Europe (Xu, Morris, Liu, \& Holden, 2018) and 27\% of the land area of Finland is covered with peatlands (Joosten, 2010; Tanneberger et al., 2017). Many (60\%) of the pristine peatlands in Europe have been subjected to a variety of anthropogenic disturbances over time, such as peat extraction, forestry, and agriculture (Vasander et al., 2003). Drainage has led to reduced biodiversity (Lehosmaa et al., 2017), greenhouse gas emissions (Maljanen et al., 2007), nutrient leaching (Tuukkanen et al., 2016), sediment erosion (Marttila \& Kløve, 2010), and leaching of acidity and metals (Saarinen, Celebi, \& Kløve, 2013).

Peatland use for extraction and other purposes involves drainage of the peatland itself and, in some cases, also adjacent river systems and land areas. Drainage lowers the natural shallow water table in peatlands (Kløve \& Bengtsson, 1999; Shantz \& Price, 2006; Strack, 2008), which results in decomposition of the upper living layer and release of significant amount of greenhouse gases to the atmosphere (Parish et al., 2008). Anthropogenic disturbance of peatlands changes the natural peatland surface and modifies peat-forming plant assemblage (Mazerolle, 2003; Poulin, Rochefort, \& Desrochers, 1999). Drainage changes the physical (Hobbs, 1986), hydraulic and biogeochemical properties of peat (Heikkinen, Ihme, Osma, \& Hartikainen, 1995; Postila et al., 2014). Peatland drainage also significantly changes the natural flow paths (Holden, Chapman, \& Labadz, 2004; Holden, Evans, Burt, \& Horton, 2006; Menberu et al., 2016), which can result in increased peak flow and increased volume and duration of runoff (Ballard, McIntyre, \& Wheater, 2012; Gregory et al., 1984; Holden et al., 2006; Robinson, 1985). In Finland, pristine peatlands are widely used to treat runoff of peat extraction, peatland forestry, mining effluents and wastewater (Postila et al., 2014). Due to rewetting and increase nutrient inputs, this leads to considerable change in vegetation and other characteristics of the wetland (Haapalehto, Vasander, Jauhiainen, Tahvanainen, \& Kotiaho, 2011; Postila et al., 2014; Postila, Karjalainen, \& Kløve, 2017). However, the impacts on the surrounding areas around the peat extraction area is not well understood and quantified.

This study sought to develop a method for examining the effects of peat extraction on changes in surrounding wetlands using remote sensing analysis of pre- and post-extraction Landsat images and quantifying the normalized difference vegetation index (NDVI). Remote sensing can provide important information at landscape scale on habitat conditions, leading national conservation bodies to recognize its crucial input to environmental monitoring studies (Cole, McMorrow, \& Evans, 2013). Hence, remote sensing techniques, using the Landsat MSS, Landsat Tm, and SPOT satellite systems, have been employed to study almost all types of wetlands and peatlands (Dronova, 2015; Ozesmi \& 
Bauer, 2002). Landsat MSS satellite images were used in this study, as time series of these images are available since 1970's. A few previous studies have used remote sensing techniques to study peatland-related issues, e.g., wetland detection and wetland vegetation mapping (Beamish, 2013; Cole et al., 2013; Dabrowska-Zielinska et al., 2014; Kalacska et al., 2013). However, to the best of our knowledge, this study is the first to apply remote sensing methods to analyse peat extraction effects on adjacent wetlands and surrounding areas. The NDVI was used here to develop a new technique, which we call EABRA (Environmental Impact Assessment Based on Reference Area), that quantifies land degradation by comparing Landsat images of impacted areas with images of reference surrounding areas. The overall objective of this study was to determine the feasibility of applying remote sensing techniques on a small scale to investigate the impacts of peat extraction on the peatland site itself and surrounding wetlands.

\section{Material and Methods}

\subsection{Study areas}

The study was conducted at a peat extraction site located in Korentosuo in northern Ostrobothnia, Finland $\left(64^{\circ} 52^{\prime} 34^{\prime \prime} \mathrm{N}, 26^{\circ} 49^{\prime} 28^{\prime \prime} \mathrm{E}\right)$ (Figs. 1a and 1b). The climate in the area is cold, with permanent snow cover lasting for approximately 160-175 days (Eskelinen, Ronkanen, Marttila, \& Kløve, 2016). Mean annual precipitation in the area is approximately $600 \mathrm{~mm}$ and mean annual temperature is $2{ }^{\circ} \mathrm{C}$ (Mohammadighavam \& Klöve, 2016). The topography of the area is relatively flat, with most of the area lying below $200 \mathrm{~m}$ a.s.l. (Eskelinen, Ronkanen, Marttila, \& Kløve, 2016). The peat extraction site itself occupies an area of approximately 210 ha and prior to peat extraction was covered by vegetation (Fig. 1c). Peat extraction began in 2010 and is planned to run for at least 20 years (Eskelinen et al., 2016). The cut-over peat extraction area is covered with decomposed peat with no vegetation (Fig. 1f) and has $1 \mathrm{~m}$ wide open drains set at $20 \mathrm{~m}$ spacing (Figs. 1b, 1c and 1d). With the exception of a pilot area (Fig. 1b), cut-off drains have been dug around the site to prevent influx of external water into the extraction site. Adjacent to the outlet of the peat extraction site, a section of the mires has been used as a constructed wetland to which peat extraction runoff water discharge. At this site, large hydraulic loading and nutrient inputs have changed the vegetation.

Overall, four possible impacts could be expected for Korentosuo peat extraction and surrounded area:

I. Land cover change trough the peat extraction process (change vegetation to bare peat surface),

II. Hydrological changes (drainage, water table change and flow regime change) in the peat extraction area after drainage area, 
III. Hydrological changes in the downstream areas due to hydrological changes related to peat extraction area and the surrounding ditches (changed fluxes, lowered groundwater table) and also pumping extra flow through the wetland),

IV. Climatological change due to natural climate variability over the entire studied area.

Based on these four hypothesized impacts. We defined three differently impacted areas (for the Korentosuo case): The first area is located inside of the peat extraction area, where we supposed to experience impacts \#1, \#2 and \#4, and hence we categorize this area as highly impacted area (Fig. 2). We defined nine sample areas inside of peat extraction namely (Ap-Ip which $\mathrm{p}$ stand for peat extraction area). The second group is located downstream of the peat extraction area, where we assume were affected by impacts \#3 and \#4 and this area is categorized as medium impacted area hereafter named adjacent wetland (Gs, W and Fs in Fig. 2). The third area is located around the peat extraction area, excluding the downstream part of the peat extraction area. In this area, we have only impact \#4, and we categorized this as low impact area (all sample area which ended to s except Gs and Fs in Fig. 2, s is stand for surrounded sample area). These areas can be clearly verified by visual inspection of Fig. 1 that shows the different vegetation cover in the peat extracted area and the surrounding wetlands. The vegetation change in adjacent wetland and the land cover of selected area were verified by visiting studied area.

\subsection{Remote sensing applications for detection of wetland land cover changes}

The assessment method was developed to evaluate the main change in vegetation and land cover, which was quantified using NDVI. The NDVI is a numerical indicator that uses the visible and nearinfrared bands of the electromagnetic spectrum and is designed to analyse remote sensing measurements and assess whether the target area contains living green vegetation or not. It comprises a standard algorithm designed to estimate the amount of above-ground green vegetation cover from measurements of red and near-infrared reflectance. The NDVI is more widely used than simple forms of vegetation index and employs a scale ranging between -1 for snow and ice and +1 for complete vegetation cover (Kumar \& Shekhar, 2015). Based on available images for analysis, in the present study NDVI was determined using equations 1 and 2.

$$
N D V I_{T M}=\frac{B 2-B 4}{B 2+B 4}
$$


$N D V I_{O L I}=\frac{B 3-B 5}{B 3+B 5}$

where B2 and B4 are top-of-atmosphere (TOA) or surface reflectance at red and near infrared, respectively, in Landsat TM, and B3 and B5 are TOA or surface reflectance at red and near infrared, respectively, in Landsat OLI. The vegetation conditions in the wetland adjacent to the peat-mining site before and after peat extraction were analysed using Landsat multispectral images, which are freely available from the USGS dataset (http://earthexplorer.usgs.gov/). The NDVI values for preand post- peat extraction conditions at the study site were calculated using 24 images taken from preand post-extraction periods. All images belonged to Path 188, 189, and 190 and Row 014, 015, with spatial resolution $30 \mathrm{~m}$. The parameters used in remote sensing indices require physical units, such as at-sensor radiance or TOA reflectance, rather than raw quantized calibrated pixel values (digital numbers, DN). Hence, we converted Landsat TM and Landsat OLI DN to TOA reflectance using preprocessing tools in ENVI 5.1 (Li et al., 2015).

\subsection{NDVI as a tool for peat extraction impact assessment}

The NDVI of impacted wetlands can be expected to vary between two thresholds, the upper threshold being the NDVI of natural conditions in the impacted area (NDVI $\mathrm{NC}_{\mathrm{NC}}$ ) with proper conditions for wetland vegetation, and the lower threshold $\left(\mathrm{NDVI}_{\mathrm{LT}}\right)$ being the minimum possible NDVI at maximum land degradation and/or in the worst possible conditions for vegetation. The lower NDVI threshold is the transformed state of wetland to bare soil (Fig. 1). Hence, to evaluate the impact of peat extraction on each date, the minimum NDVI of the peat extraction site (NDVI peat) on that date was taken as the lower threshold for NDVI. To estimate NDVI $\mathrm{LT}_{\mathrm{L}}$, nine sample areas (Ap-Ip) were selected within the peat extraction site (Fig. 2). By considering the two thresholds, we devised the following equation (Eq. 3) to quantify the impact (I) of peat extraction on the extraction site and/or adjacent wetlands:

$I=\frac{\left(N D V I_{N C}-N D V I_{I A}\right)}{\left(N D V I_{N C}-N D V I_{L T}\right)} \times 100$

where $\mathrm{NDVI}_{\mathrm{NC}}, \mathrm{NDVI}_{\mathrm{IA}}$, and $\mathrm{NDVI}_{\mathrm{LT}}$ represent the NDVI of natural condition of impacted areas (NC), impacted areas (IA), and lower threshold (LT), for our study this is the peat extraction area as as it has bare soil), respectively. $\mathrm{NDVI}_{\mathrm{IA}}$ and $\mathrm{NDVI}_{\mathrm{LT}}$ were calculated directly for dates of interest from available images. A model is needed to estimate the NDVI of initial condition for an impacted 
area at a given date for a given condition (weather, vegetation, sun radiation). The NDVI $\mathrm{NC}_{\mathrm{NC}}$ was calculated using a concept defined as Reference Surrounding Area (RSA), which is a reference area that show the closest relationship with the NDVI of the impacted area during the pre-extraction period. To define the RSA, 16 sample areas surrounding the peat extraction site were selected (polygons As-Ps in Fig. 2). The RSA showing the highest linear regression coefficient $\left(\mathrm{R}^{2}\right)$ with the NDVI of the impacted area was selected (Eq. 4) as NDVI $\mathrm{NC}_{\text {. }}$

$y=m x+b$

where $\mathrm{x}, \mathrm{y}$ is the NDVI for RSA and impacted area, respectively, obtained from same date image in pre-impact period. The shape and size of the RSAs were chosen based on the polygon of impacted area (polygon W in Fig. 2).

In order to evaluate the impact of peat extraction (Eq. 3), 15 sample areas were selected, of which nine, three, and three sample areas were expected to experience a high, medium, and low impact respectively as explained in study area description. The nine sample areas expected to receive the highest impact (Ap-Ip, referred as group one) were all located within the peat extraction site (Fig. 2), since they are hotspots of the peat extraction process. The three sample areas (W, Fs, and Gs), located downstream of the peat extraction site, were expected to experience a medium impact and were included in group two. The three sample areas (Ps, Os, and Ns in Fig. 2) expected to receive the lowest impact because of their advantageous location (upstream of the peat extraction site) were included in group three. These can be clearly verified from Fig. 1 and from site inspection.

\section{Results and discussion}

\subsection{Variations in NDVI}

Based on the 24 images analysed for the As-Ps sample areas (Figs. 3 and 4), the NDVI of the surrounding area ranged from 0.6 to 0.64 (Fig. 5a, 5b). During the pre-extraction period (Fig. 3), the average, maximum, and minimum NDVI value at the study site was $0.55,0.65$, and 0.43 , respectively. However, in the post-extraction period the NDVI in peat harvesting areas (Ap-Ip) decreased significantly (negative trend, with 0.02 as significance level based on Mann-Kendal trend test), giving average, maximum, and minimum NDVI values of $0.35,0.41$, and 0.27 , respectively (Figs. $5 \mathrm{c}, 5 \mathrm{~d}$ ). 
The large variations in NDVI values for such the small study area clearly indicate that the NDVI is highly sensitive to land cover and weather changes. The considerable differences in NDVI magnitude can be seen by comparing Figs. 5d and 5a-c that shows the NDVI variation in peat extracted area, which were primarily affected by significant land cover changes. The main changes in NDVI is observed when vegetation cover change to bare soil with peat extraction. Impact of weather changes on the NDVI can be seen in the area surrounding the peat extraction area (in the area with vegetation) during the growing season. Among all images of the natural conditions at the Korentosuo site, the lowest average NDVI value (0.43) was for an image taken on June 2, 2001, and was very close to the NDVI of bare peat (Fig. 5c). This can partly be explained by temperature variations. Based on temperature records for Korentosuo, the average temperature in the 7 -day $\left(5.8^{\circ} \mathrm{C}\right)$ and 10 -day $(6.9$ ${ }^{\circ} \mathrm{C}$ ) periods ending on June 2, 2001, were the lowest for all images. Consequently, the magnitude of NDVI based on those images that are acquired out of growing season is not valid reference for estimating vegetation cover change.

\subsection{Selecting the reference surrounding area}

In order to find the RSA of the 15 areas of interest (Ap-Ip, Fs, W, Gs, Ns, Os, and Ps), the temporal linear correlation between the calculated NDVI of these areas and that of the surrounding 14 areas (As, Bs, Cs, Ds, Es, Hs, Is, Js, Ks, Ls, Ms, Ns, Os and Ps) in pre-extraction period images was determined (Fig. 6 and Table 1). This resulted in a coefficient of regression $\left(\mathrm{R}^{2}\right)$ that varied from 0.78 to 0.99 between the 17 areas of interest and the selected RSA (Table 1). The selected RSA for within the peat extraction site was Ms, since it showed the highest $R^{2}$ with Ap-Dp (Fig. 6 and Table 1). Among the 14 selected surrounding areas, As showed the closest NDVI to natural conditions in the impacted wetland area during the pre-extraction period (Fig. 6). The selected areas (RSA) were a result of NDVI analysis of 19 images taken in 1999-2009, before peat extraction. The RSAs were used to estimate $\mathrm{NDVI}_{\mathrm{NC}}$ (Eq. 3). i.e., to quantify the impact on areas of interest.

\subsection{Peat extraction impacts on Korentosuo site and surrounding areas}

Based on the post-extraction images taken during 2009-2016, the sample areas inside the peatextraction site (Ap-Ip, group1) suffered the highest impact from 76.66 to 93.44 (Table 1). For these areas of interest, the mean and mode of real and absolute impact were the same, which means that the impact in all these sample areas accrued in same direction (for all images, the numerator in Eq. 3 had same sign: positive or negative). As mentioned in section 3.2, in all peat extraction areas the NDVI during the post-extraction period decreased significantly for all images, so the numerator in Eq. 3 was 
positive, as $\mathrm{NDVI}_{\mathrm{IA}}$ was less than $\mathrm{NDVI}_{\mathrm{NC}}$. This reflects the land cover change after all the vegetation had been removed as part of the peat extraction process and green area was converted to bare peat. The main impact was lower for some of these areas (e.g., Cp and Fp) than for others, as during early extraction they were not completely affected, but the value of the mode showed more than $75 \%$ impact in these areas. This value confirm our expectation about the peat extraction area.

Among the 17 sample areas, Ns, Os, and Ps (group 3) showed the lowest impact (less than 5\% and $2 \%$ for real and absolute mean impact, respectively) (Table 1). These areas are located to the north of the peat extraction site, in a part which was not excavated and only affected by variations in climate (natural causes). In these areas, the impact was not easy to assess, owing to the high sensitivity of NDVI to weather conditions. As we expected, low impact was observed for this area.

Three downstream areas were assessed, including impacted wetlands (group 2; W, Fs, and Gs in Fig. 2). The mode of impact for $\mathrm{W}, \mathrm{Fs}$, and Gs was 34.77, 15.12, and 7.31 respectively (Table 1). For these areas the real and absolute mean and mode of impact also differed, as superposed impacts occurred due to hydrological and climatological factors. Based on field observations before and after peat extraction, the extraction area has been described as impacted wetland, further confirming the remote sensing results. The primary triggering factor behind the differences in impact in areas upstream of the peat extraction site (group 3, i.e., Ns, Os, and Ps) and at the outlet (W and Fs) was probably flow regime change (Table 1), since the latter areas are at the receiving end of most of the hydrological regime alterations.

\subsection{Data uncertainty and novelty of the findings}

NDVI is an index for monitoring vegetation area greenness and is very sensitive to environmental conditions such as rainfall, net radiation, transpiration, temperature, and anthropogenic activities. Temperature is one of the major abiotic factors affecting plant photosynthesis and may influence the spectral characteristics of chlorophyll, which plays a significant role in the greenness of plants. Depending on the type of vegetation (forest, grassland, desert, scrubland) and so on, NDVI could reflect the superposed effects of different weather and other environmental conditions in previous days, weeks, months, or even years. As a result, similar NDVI values for a particular area in different periods of time cannot be expected, as confirmed in this work (Fig. 3). As shown in Table 1, the NDVI values for a particular part of the peat extraction site during the post-extraction period were different, even if the area was bare peat. To overcome this uncertainty, for each area of interest we 
defined a reference surrounding area (RSA) that had the most similar NDVI during the pre-extraction period. Since the RSA had not been affected by anthropogenic activities, we assumed that our area of interest would have had similar characteristics if no anthropogenic disturbance had taken place. Therefore, the natural conditions in the impacted area were estimated based on the highest possible linear regression coefficient between the RSA and the impacted area. As seen in Fig. 6, there is a direct correlation between NDVIs of interested area and RSA. Increasing the NDVI from Low (poor vegetation cover) to high (dense vegetation cover) in RSA correspond to same variation in NDWI of interested area. To calculate the impact (Eq. 3) for certain date in the post impact period, we estimate

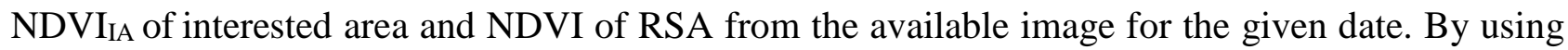
NDVI of RSA as in Eq. 4, we estimate the $\mathrm{NDVI}_{\mathrm{NC}}$ of interested areas for given date. As both $\mathrm{NDVI}_{\mathrm{NC}}$ and $\mathrm{NDVI}_{\mathrm{IA}}$ are taken from the same date (and same climate condition), the influence of climate is removed from the calculated impact by Eq. 3. This removes any uncertainty that might result from temporal variations (e.g., environmental conditions and past meteorological events), since the NDVI of natural conditions is estimated from images taken on the same date as the post-extraction images. The magnitude of uncertainty in this estimation lay in the regression coefficient $\mathrm{R}^{2}$ (Table 1 ), as the RSA is not $100 \%$ identical to the area of interest during the pre-extraction period.

The results showed that the impact of peat extraction can be determined to some degree using the remote sensing technique devised here. As the approach is based on a reference area, we named it EABRA (Environmental Impact Assessment Based on Reference Area). Comparisons between absolute mean and real mean may reveal the type of impact: when the mean values are equal, a considerable part of the impact is systematic or deterministic and mostly caused by anthropogenic disturbances such as intensive land use change. However, the observed impact can include some stochastic or random component (mostly due to natural variations such as weather). Since anthropogenic activities can have an impact on large areas and detecting or monitoring large areas can be costly or difficult, the approach developed in this study could be a viable option and can be applied quite easily. In this study, we used the method to quantify the direct impact of anthropogenic disturbances (peat extraction site), the direct impact of natural change (areas Ns, Os, and Ps), and the indirect (less severe) impact of anthropogenic disturbances by change in hydrological flux and overflow treatment on adjacent areas (W, Fs, and GS). Using remote sensing we can also identify less (or indirectly) impacted areas (FS and GS) that may be difficult to observed using ground monitoring (due to low rate of impact). In some cases, such as a low rate of impact or lack of access to impacted areas, field detection is impossible. However, using the remote sensing approach we were able to clearly identify indirectly impacted areas (FS and GS) that were undetectable in ground monitoring 
due to low rate of impact. Therefore, the method developed was able to reveal the temporal patterns and rate of expansion of the impact from peat extraction activities.

The accuracy of the method depends on the accuracy of the images taken and the spatial characteristics and resolution of the expected land use changes. As in the present case study, peat extraction cover and area of more than 100 ha, which has a uniform land cover which can easily be detected with a resolution of $30 \mathrm{~m}$ provided by Landsat. With peatland drainage, the land cover changes depend mainly on land use type (peat extraction, forestry, agriculture) and secondarily on soil properties, drainage intensity, land ownership, climate etc. In boreal regions, where large peatland systems occur, the spatial changes are large generally large enough to be detected by Landsat. In smaller peatland systems, Landsat accuracy would probably not be sufficient and other products such as SWIR channels instead of NIR and VIS channels for peatland/wetland change assessment. Also, Landsat would probably not be so suitable to detect small spatial changes due to restoration or rewetting as these occur at a small scale typically similar to the drainage intensity or smaller. Also observing accurately changes on forestry drained sites would require a different approach as forestry changes due to cutting practices etc. on a scale that is variable between sites. The main goal for the presented method was to assess the impact of peat extraction area on the surrounding wetlands, which is difficult to detect by other methods than Landsat as data records or satellite images are not available for the time period before or immediately after peatland extraction started (after the oil crisis in 1973).

\section{Conclusions}

Large scale peat extraction started in several countries after the oil crisis in 1973. Peat extraction has the potential to impact nearby wetlands. However, monitoring such changes is challenging, as data is normally not available. In the presented work, we use a novel remote sensing method (EABRA), to quantify direct and indirect impacts of drainage and peat extraction. The method proved to be a useful way to analyse environmental impacts of peat extraction that occur on a scale of about 100 ha. The NDVI values for the peat extraction site (bare peatland) and vegetated peatlands under normal climate conditions varied between 0.30-0.45 and 0.55-0.70, respectively. However, the NDVI for vegetated peatlands in cold weather conditions (e.g. for this work 10 days mean temperature $<7^{\circ} \mathrm{C}$ ) resembled that of a bare peatland (NDVI $=0.40$ ). This clearly shows the sensitivity of NDVI to meteorological conditions and indicates that great care is needed when quantifying NDVI in areas with varying weather conditions. Impact assessment of a small peatland area transformed from vegetated peatland to bare peatland is possible using the developed approach, as it can easily detect visual changes and 
assess adjacent areas. The results are promising and agree with expectations and previously reported changes. The method can be used in future studies subjected to a variety of other natural and/or anthropogenic disturbances on peat soils. As the accuracy of Landsat is about $30 \mathrm{~m}$, the method is recommended for large peatland systems and to study impact of drainage and not to assess small scale land cover changes such effect or rewetting or restoration.

\section{References}

Ballard, C. E., McIntyre, N., \& Wheater, H. S. (2012). Effects of peatland drainage management on peak flows. Hydrology and Earth System Sciences, 16(7), 2299-2310. https://doi.org/10.5194/hess-16-2299-2012

Beamish, D. (2013). Peat mapping associations of airborne radiometric survey data. Remote Sensing, 6(1), 521-539. https://doi.org/10.3390/rs6010521

Cole, B., McMorrow, J., \& Evans, M. (2013). Empirical modelling of vegetation abundance from airborne hyperspectral data for upland peatland restoration monitoring. Remote Sensing, 6(1), 716-739. https://doi.org/10.3390/rs6010716

Dabrowska-Zielinska, K., Budzynska, M., Tomaszewska, M., Bartold, M., Gatkowska, M., Malek, I., .. Napiorkowska, M. (2014). Monitoring wetlands ecosystems using ALOS PALSAR (Lband, HV) supplemented by optical data: A case study of biebrza wetlands in northeast poland. Remote Sensing, 6(2), 1605-1633. https://doi.org/10.3390/rs6021605

Dronova, I. (2015). Object-based image analysis in wetland research: A review. Remote Sensing, 7(5), 6380-6413. https://doi.org/10.3390/rs70506380

Eskelinen, R., Ronkanen, A. -., Marttila, H., \& Kløve, B. (2016). Assessment of uncertainty in constructed wetland treatment performance and load estimation methods. Environmental Monitoring and Assessment, 188(6). https://doi.org/10.1007/s10661-016-5381-5 
Gregory, J. D., Skaggs, R. W., Broadhead, R. G., Culbreath, R. H., Bailey, J. R., \& Foutz, T. L. (1984). Hydrologic and water quality impacts of peat mining in North Carolina. Water Resources Research Institute of the University of North Carolina, Raleigh, United States. Retrieved from http://www.lib.ncsu.edu/resolver/1840.4/1837

Haapalehto, T. O., Vasander, H., Jauhiainen, S., Tahvanainen, T., \& Kotiaho, J. S. (2011). The effects of peatland restoration on water-table depth, elemental concentrations, and vegetation: 10 years of changes. Restoration Ecology, 19(5), 587-598. https://doi.org/10.1111/j.1526100X.2010.00704.X

Heikkinen, K., Ihme, R., Osma, A. -., \& Hartikainen, H. (1995). Phosphate removal by peat from peat mining drainage water during overland flow wetland treatment. Journal of Environmental Quality, 24(4), 597-602. https://doi.org/10.2134/jeq1995.00472425002400040007x

Hobbs, N. B. (1986). Mire morphology and the properties and behaviour of some british and foreign peats. Quarterly Journal of Engineering Geology, 19(1), 7-80. https://doi.org/10.1144/GSL.QJEG.1986.019.01.02

Holden, J., Chapman, P. J., \& Labadz, J. C. (2004). Artificial drainage of peatlands: Hydrological and hydrochemical process and wetland restoration. Progress in Physical Geography, 28(1), 95-123. doi:10.1191/0309133304pp403ra

Holden, J., Evans, M. G., Burt, T. P., \& Horton, M. (2006). Impact of land drainage on peatland hydrology. Journal of Environmental Quality, 35(5), 1764-1778. https://doi.org/10.2134/jeq2005.0477 
Joosten, H. (2010). The global peatland CO2 picture: Peatland status and drainage related emissions in all countries of the world. Wetland International, Ede, Netherlands. Retrieved from https://www.wetlands.org/publications/the-global-peatland-co2-picture/

Kalacska, M., Arroyo-Mora, J. P., de Gea, J., Snirer, E., Herzog, C., \& Moore, T. R. (2013). Videographic analysis of eriophorum vaginatum spatial coverage in an ombotrophic bog. Remote Sensing, 5(12), 6501-6512. https://doi.org/10.3390/rs5126501

Kløve, B., \& Bengtsson, L. (1999). Runoff generation in a plough-drained cutover fen in central finland. Journal of Hydrology, 218(3-4), 157-168. https://doi.org/10.1016/S00221694(99)00036-0

Kumar, D., \& Shekhar, S. (2015). Statistical analysis of land surface temperature-vegetation indexes relationship through thermal remote sensing. Ecotoxicology and Environmental Safety, 121, 39-44. https://doi.org/10.1016/j.ecoenv.2015.07.004

Lehosmaa, K., Jyväsjärvi, J., Virtanen, R., Ilmonen, J., Saastamoinen, J., \& Muotka, T. (2017). Anthropogenic habitat disturbance induces a major biodiversity change in habitat specialist bryophytes of boreal springs. Biological Conservation, 215, 169-178. https://doi.org/10.1016/j.biocon.2017.09.010

Maljanen, M., Hytönen, J., Mäkiranta, P., Alm, J., Minkkinen, K., Laine, J., \& Martikainen, P. J. (2007). Greenhouse gas emissions from cultivated and abandoned organic croplands in Finland. Boreal Environment Research, 12(2), 133-140. Helsinki, Finland. Retrieved from https://jukuri.luke.fi/bitstream/handle/10024/513694/Maljanen.pdf?sequence=1 
Marttila, H., \& Kløve, B. (2010). Dynamics of erosion and suspended sediment transport from drained peatland forestry. Journal of Hydrology, 388(3-4), 414-425. https://doi.org/10.1016/j.jhydrol.2010.05.026

Mazerolle, M. J. (2003). Detrimental effects of peat mining on amphibian abundance and species richness in bogs. Biological Conservation, 113(2), 215-223. https://doi.org/10.1016/S00063207(02)00360-9

Menberu, M. W., Tahvanainen, T., Marttila, H., Irannezhad, M., Ronkanen, A. -., Penttinen, J., \& Kløve, B. (2016). Water-table-dependent hydrological changes following peatland forestry drainage and restoration: Analysis of restoration success. Water Resources Research, 52(5), 3742-3760. https://doi.org/10.1002/2015WR018578

Mohammadighavam, S., \& Klöve, B. (2016). Evaluation of DRAINMOD 6.1 for hydrological simulations of peat extraction areas in northern finland. Journal of Irrigation and Drainage Engineering, 142(11). https://doi.org/10.1061/(ASCE)IR.1943-4774.0001086

Ozesmi, S. L., \& Bauer, M. E. (2002). Satellite remote sensing of wetlands. Wetlands Ecology and Management, 10(5), 381-402. https://doi.org/10.1023/A:1020908432489

Parish, F., Sirin, A., Charman, D., Joosten, H., Minayeva, T., Silvius, M., \& Stringer, L. (2008). Assessment on peatlands, biodiversity and climate change: Main report. Global Environment Centre, Kuala Lumpur \& Wetlands International, Wageningen, The Netherlands.

Postila, H., Karjalainen, S. M., \& Kløve, B. (2017). Can limestone, steel slag or man-made sorption materials be used to enhance phosphate-phosphorus retention in treatment wetland for peat extraction runoff with low phosphorous concentration? Ecological Engineering, 98, 403-409. https://doi.org/10.1016/j.ecoleng.2016.05.042 
Postila, H., Saukkoriipi, J., Heikkinen, K., Karjalainen, S. M., Kuoppala, M., Marttila, H., \& Kløve, B. (2014). Can treatment wetlands be constructed on drained peatlands for efficient purification of peat extraction runoff? Geoderma, 228-229, 33-43.

https://doi.org/10.1016/j.geoderma.2013.12.008

Poulin, M., Rochefort, L., \& Desrochers, A. (1999). Conservation of bog plant species assemblages: Assessing the role of natural remnants in mined sites. Applied Vegetation Science, 2(2), 169180. https://doi.org/10.2307/1478980

Robinson, M. (1985). The hydrological effects of moorland gripping: A re-appraisal of the moor house research. Journal of Environmental Management, 21(3), 205-211. United States.

Saarinen, T., Celebi, A., \& Kløve, B. (2013). Links between river water acidity, land use and hydrology. Boreal Environment Research, 18(5), 359-372, Helsinki, Finland. Retrieved from https://helda.helsinki.fi/bitstream/handle/10138/229470/ber18-5-359.pdf?sequence=1

Shantz, M. A., \& Price, J. S. (2006). Characterization of surface storage and runoff patterns following peatland restoration, quebec, canada. Hydrological Processes, 20(18), 3799-3814. https://doi.org/10.1002/hyp.6140

Strack, M. (Ed.). (2008). Peatlands and climate change. Jyväskylä, Finland: International Peat Society. Retrieved from http://www.peatsociety.org/sites/default/files/files/PeatlandsandClimateChangeBookIPS2008.p df

Tanneberger, F., Tegetmeyer, C., Busse, S., Barthelmes, A., Shumka, S., Mariné, A. M., . . . Joosten, H. (2017). The peatland map of europe. Mires and Peat, 19 https://doi.org/10.19189/MaP.2016.OMB.264 
Tuukkanen, T., Stenberg, L., Marttila, H., Finér, L., Piirainen, S., Koivusalo, H., \& Kløve, B. (2016). Erosion mechanisms and sediment sources in a peatland forest after ditch cleaning. Earth Surface Processes and Landforms, 41(13), 1841-1853. https://doi.org/10.1002/esp.3951

Vasander, H., Tuittila, E. -., Lode, E., Lundin, L., Ilomets, M., Sallantaus, T., . . Laine, J. (2003). Status and restoration of peatlands in northern europe. Wetlands Ecology and Management, 11(1-2), 51-63. https://doi.org/10.1023/A:1022061622602 
Xu, J., Morris, P. J., Liu, J., \& Holden, J. (2018). PEATMAP: Refining estimates of global peatland distribution based on a meta-analysis. Catena, 160, 134-140. 


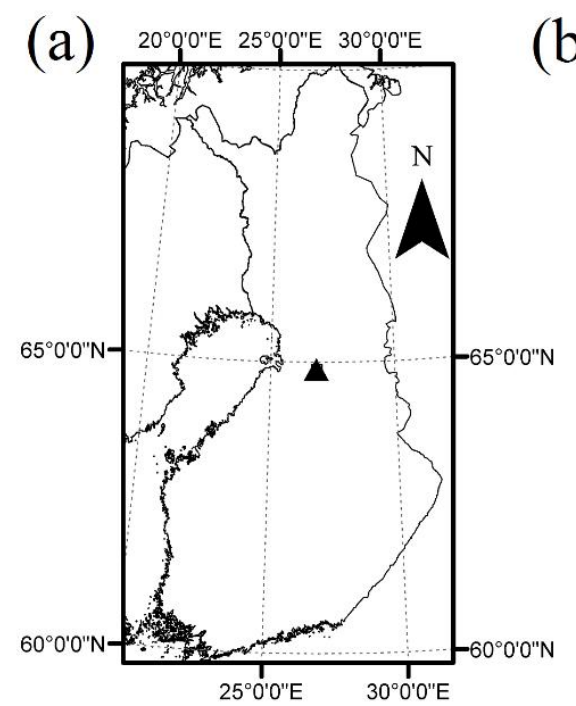

(b)

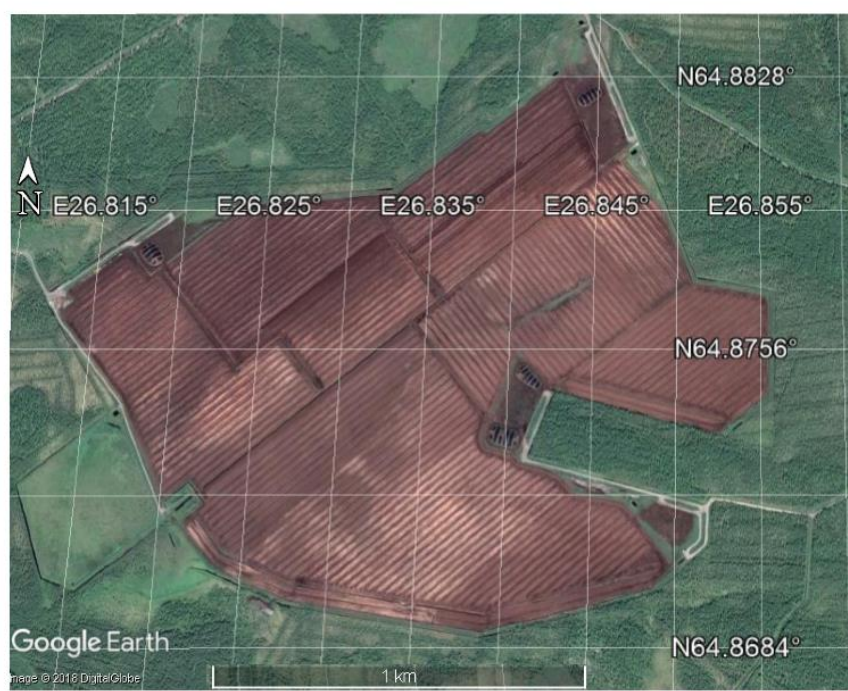

(c)
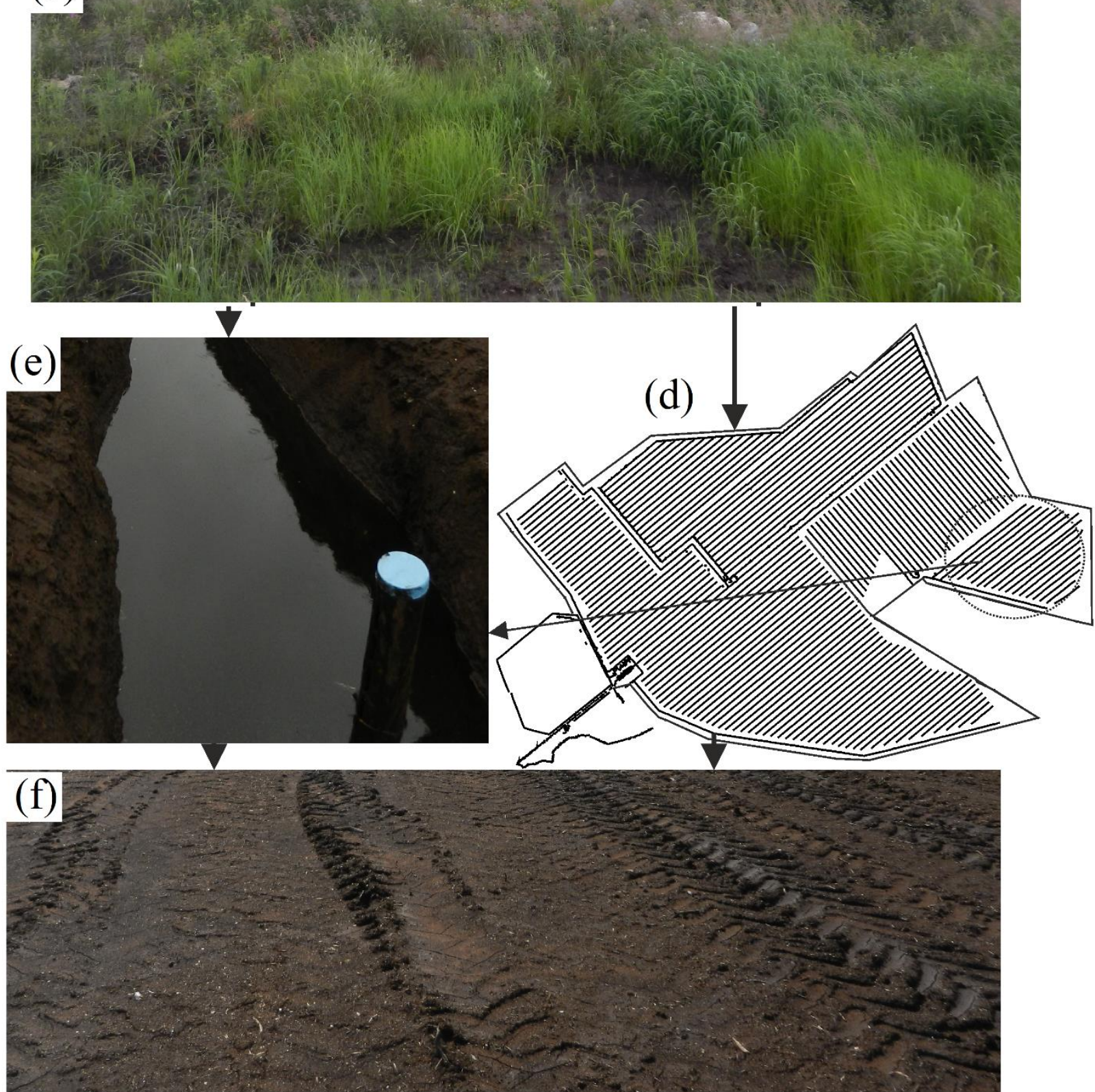
Fig. 1. a and b) location of the study site in Finland, c) Pristine vegetation at the peat extraction site, d) the drainage network installed before extraction, e) a typical ditch and f) post-harvesting surface conditions.

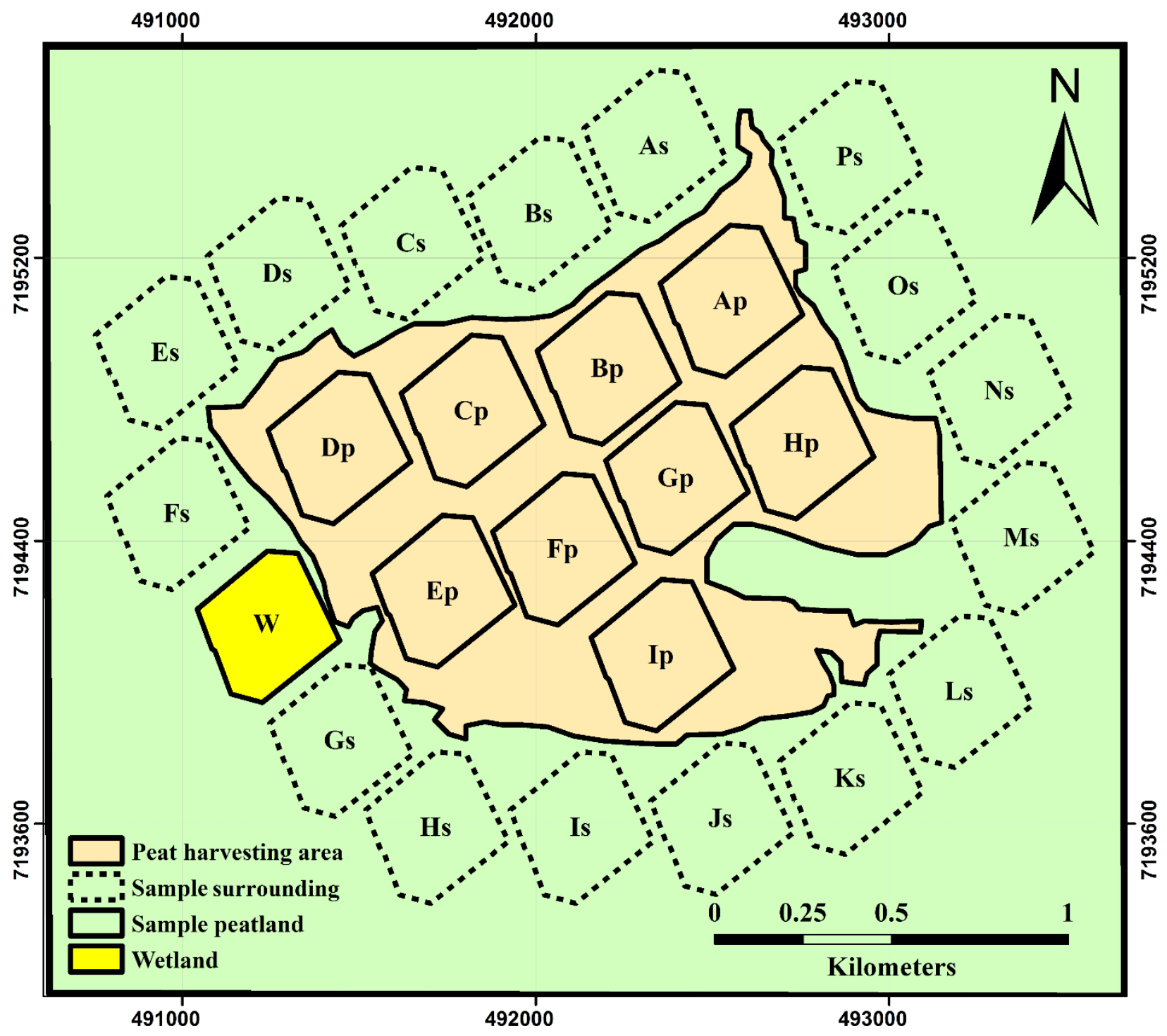

Fig. 2. Layout of sample areas in the Korentosuo peatland. Ap-Ip: peat extraction areas, As-Ps: surrounding areas, W: impacted wetland. 


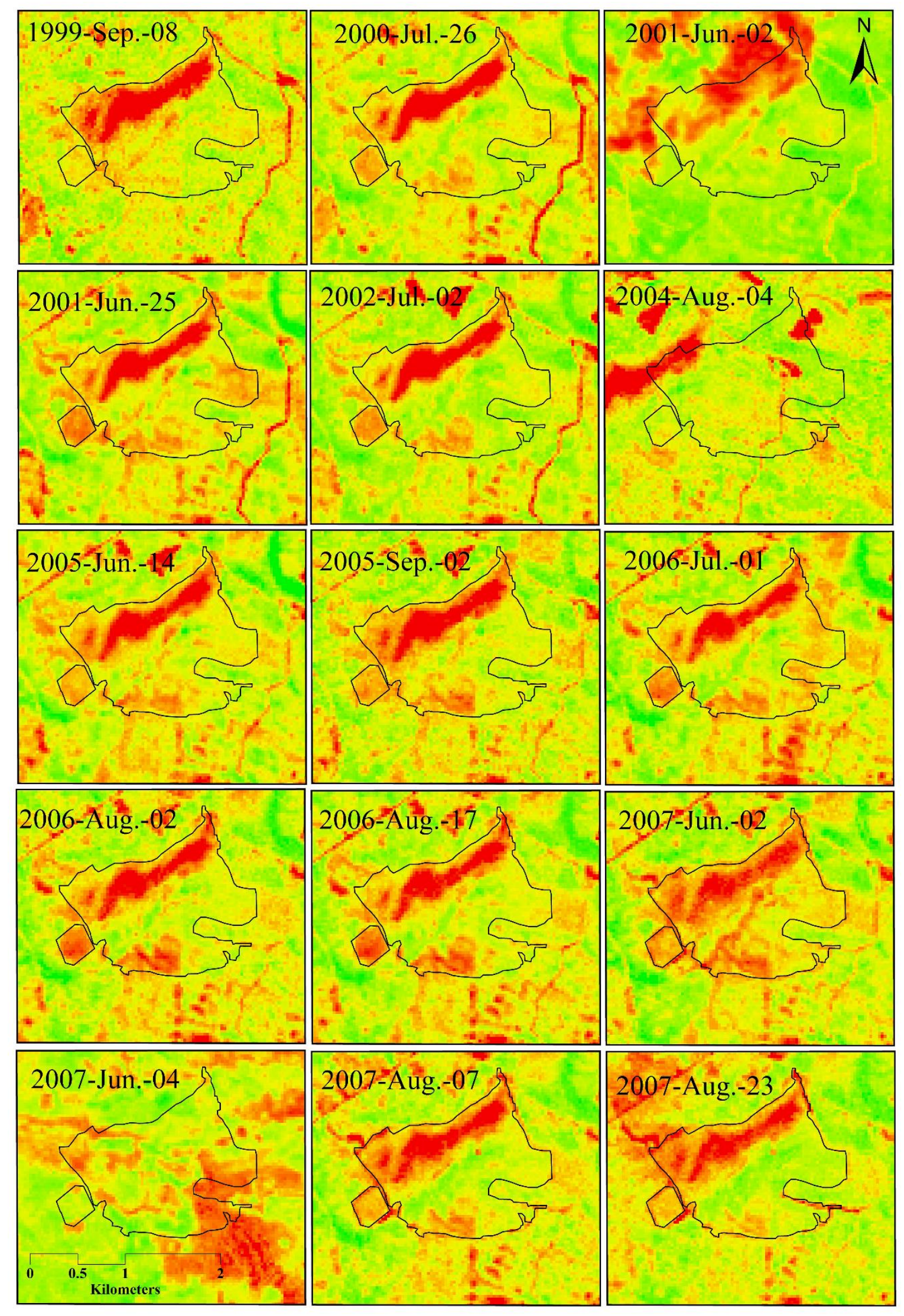

Fig. 3. Normalized difference vegetation index (NDVI) maps of the Korentosuo peat extraction area and surrounding area in the pre-extraction period. 


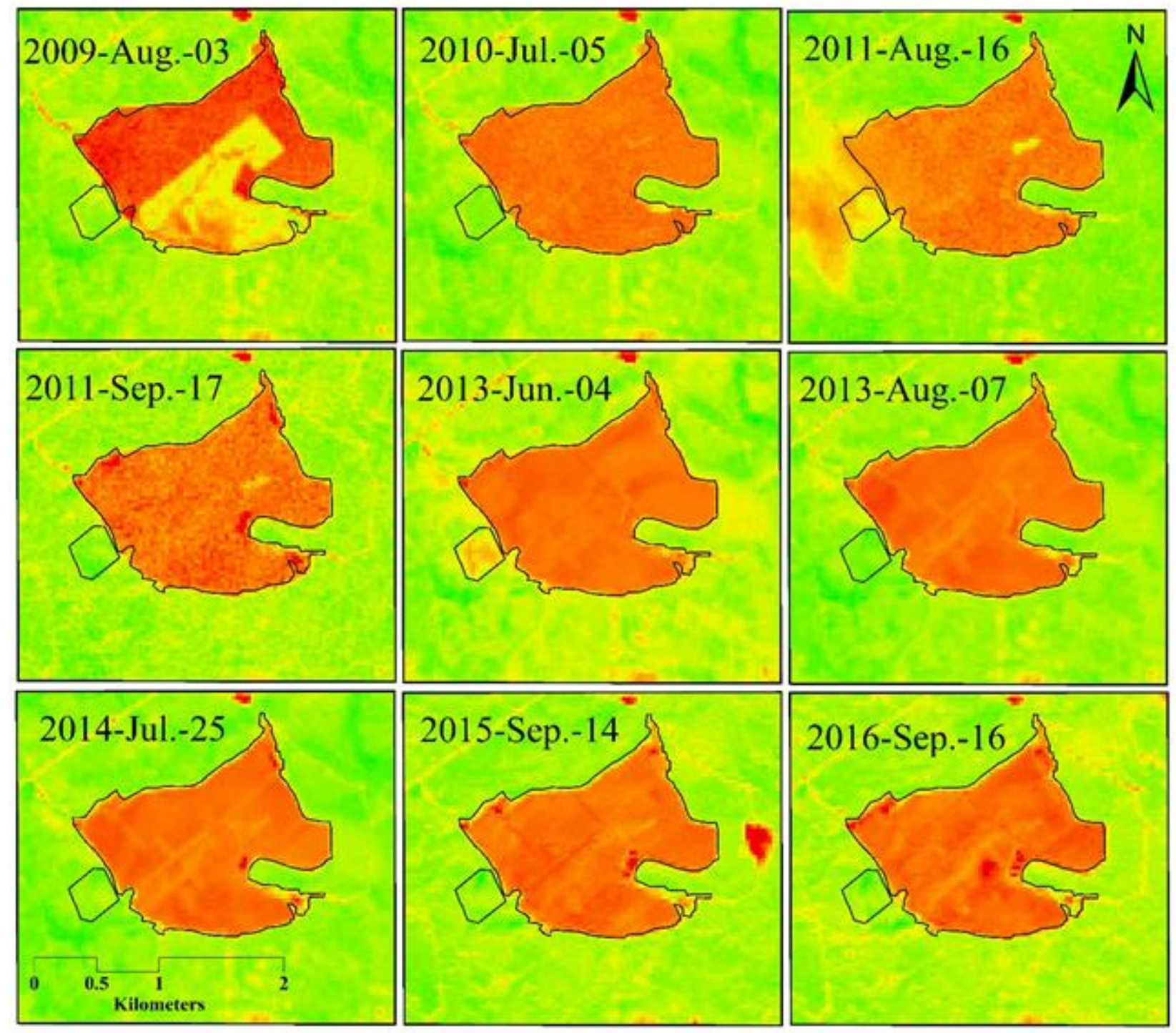

Fig. 4. Normalized difference vegetation index (NDVI) maps of Korentosuo peat extraction site and surrounding areas during the post-extraction period. 

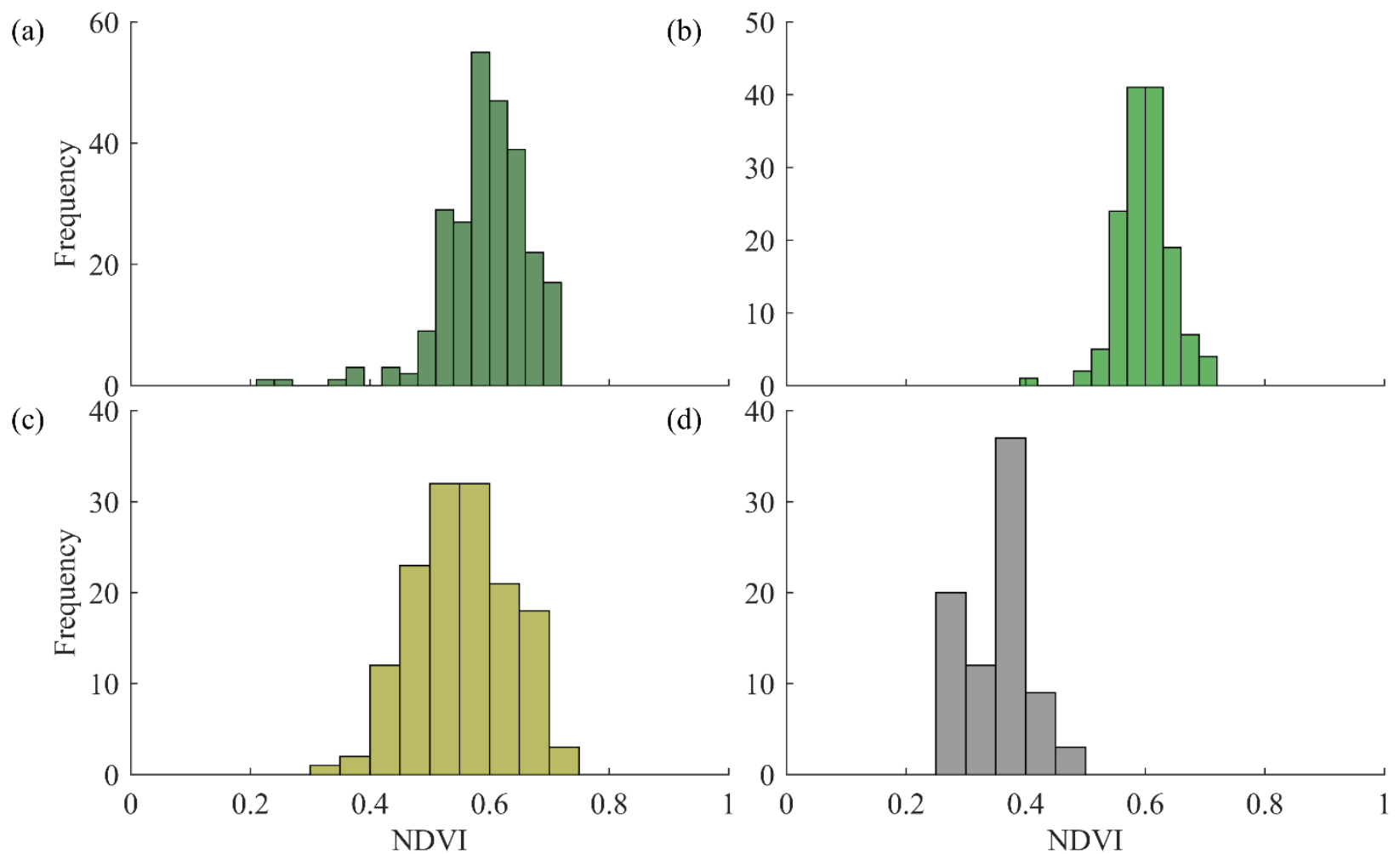

Fig. 5. Variation in normalized difference vegetation index (NDVI) in: a) surrounding areas preextraction, b) surrounding areas post-extraction, c) peat harvesting areas pre-extraction, and d) peat harvesting areas post-extraction. 


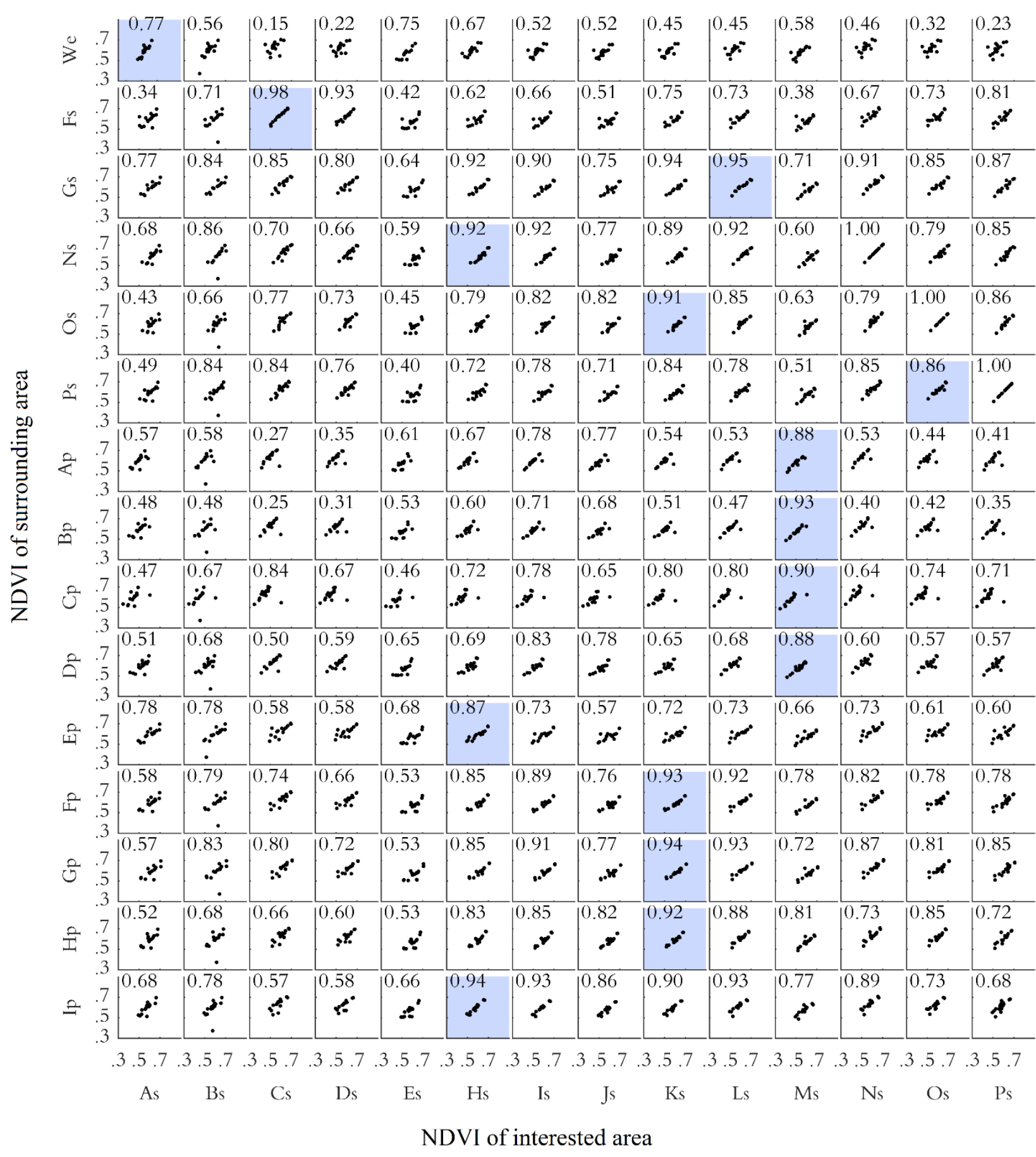

Fig. 6. Relationship between the normalized difference vegetation index (NDVI) of impacted wetland areas (y-axis) and the NDVI of surrounding areas (x-axis) during the pre-extraction period). 
